\title{
A Critical Review of Environmental Sustainability Reporting in the Consumer Goods Industry: Greenwashing or Good Business?
}

\author{
Martha C. Wilson ${ }^{1}$ \\ ${ }^{1}$ College of Business Administration, California State University, Sacramento, CA, USA \\ Correspondence: Martha C. Wilson, College of Business Administration, California State University, Sacramento, \\ CA 95819-6088, USA. Tel: 1-916-278-7198. E-mail: mcwilson@csus.edu
}

Received: April 11, 2013

Accepted: May 21, $2013 \quad$ Online Published: November 18, 2013

doi:10.5539/jms.v3n4p1

URL: http://dx.doi.org/10.5539/jms.v3n4p1

\begin{abstract}
As U.S. firms have extended their global reach to embrace new sources of suppliers, they have also been faced with increased pressures to demonstrate that they are socially and environmentally responsible by adhering to sustainable supply chain management practices. Many firms have therefore embraced "sustainability reporting" as a means of ensuring all stakeholders that they are paying attention to their social and environmental impacts while also maintaining their economic viability.

Although guidelines for sustainability reporting have been developed by various international organizations, including the World Resources Institute, the World Business Council on Sustainable Development and the United Nations, sustainability reporting and the reporting framework are voluntary endeavors. As a result, the guidelines may not be followed, and incomplete reporting or inconsistent reports may be disseminated.

The objective of this research is to identify common reporting practices as well as discrepancies in environmental reporting of selected U.S.-based consumer goods companies. These global companies are also transporting and distributing products worldwide, giving rise to the second objective of this research which is to summarize environmental reporting practices with respect to transportation and distribution.

This research shows that the companies reviewed for this study under-reported carbon emissions and greenhouse gases, often omitting emissions resulting from transportation and distribution; changed performance metrics between reporting periods; and generally engaged in inconsistent reporting practices. The research also shows that upstream supply chain partners tend to provide more thorough reports regarding environmental impacts than downstream supply chain partners.
\end{abstract}

Keywords: sustainability, environmental impacts, supply chain, transportation

\section{Introduction and Background}

As U.S. firms have extended their global reach to embrace new sources of suppliers in order to improve economic performance, they have also been faced with increased pressures to demonstrate that they are socially and environmentally responsible by adhering to sustainable supply chain management practices. With the expansion of supply chains across the globe, interest in supply chain sustainability has been receiving more attention, particularly among industrialized nations. Pressure from public interest groups, non-governmental organizations, stakeholders, and customers has certainly contributed to this renewed interest in sustainability. Companies' reputations, along with their economic performance, have declined when their environmental or employment practices have resulted in damage to the environment or the well-being of their employees. Therefore, it behooves corporations to publicize their achievements not only in terms of their economic successes, but also with regard to positive impacts they make upon society and the environment. These successes are often reported in a company's Corporate Social Responsibility (CSR) report, alternatively identified as a "sustainability report", "corporate citizenship report", or "global responsibility report". Regardless of the title of these reports, they have become more commonplace and frequently appear on company websites, addressing environmental, social, and economic performance.

Although a considerable amount of research has addressed various issues associated with social and environmental performance in supply chains, research regarding the environmental performance of the transportation of goods remains sparse. Transportation represents a key component of the supply chain, and 
research increasingly recognizes the impact that transportation can have upon the overall supply chain (Sanchez, 2010). Nevertheless, Golicic, Boerstler and Ellram (2010) state that "Supply chain management has largely overlooked the greenhouse gas impact of transportation decisions."

Reporting guidelines attempt to capture this oversight, but progress appears slow. The World Resources Institute (WRI) and the World Business Council on Sustainable Development (WBCSD) have created standards for businesses to assist them in the creation of their own greenhouse gas (GHG) inventories (WRI \& WBCSD, 2011). This "Corporate Standard" includes a "Scope 3 Standard" that is intended to guide companies in their reporting of emissions associated with supply chain/value chain activities, including transportation and distribution of goods as well as business travel. This standard is also known as the Greenhouse Gas (GHG) Protocol.

Guidelines have also been developed by the Global Reporting Initiative (GRI), a non-profit organization that provides guidance for sustainable reporting through its global network of experts and strategic partners: the Organisation for Economic Cooperation and Development (OECD), the United Nations Environment Programme, the UN Global Compact, and the International Organization for Standardization (IS0). The framework developed by GRI includes guidelines for economic, environmental, and social responsibility reporting, defining categories or "aspects" that should be included in CSR reports. Within the environmental category, transportation is one of these aspects (Global Reporting Initiative. Sustainability Reporting Guidelines, 2000-2011).

Companies may choose to adopt the GHG reporting standard, the GRI reporting framework, or another framework that they deem more appropriate for their organization. Corporate Register.com, a global directory of CSR reports, reported that forty percent of the more than 5000 reports filed as of 2011 adopted the Global Reporting Initiative (GRI) framework (CR Reporting Awards, 2012). Corporate Register notes that:

A pattern we have also previously identified is that many of the world's leading reporting countries (the UK, Japan and Germany are three of the four leading CR reporting countries) are precisely those where reporters are most reluctant to adopt the framework. This is such a striking phenomenon that it appears worthy of research.

Clearly, there is a lack of standardization among reporting organizations, in spite of the existence of guidelines. This lack of standardization leads to the question posed by this research: To what extent are CSR reports consistently reporting the impact of value chain activities, specifically those associated with the transportation and distribution of goods throughout the value chain?

\subsection{Research Objective}

The objective of this research is twofold. The first objective is to identify common practices as well as discrepancies in environmental reporting of selected U.S.-based companies. The second objective is to summarize environmental reporting practices with respect to transportation and distribution. This paper will address commonalities and differences between reporting companies, and also identify "gaps" where environmental impacts are not reported.

In order to achieve this objective, CSR reports were reviewed for selected companies in the consumer goods industry. The methodology for selecting the companies is presented in the next section along with the criteria used to assess company reports.

\section{Methodology}

\subsection{Company Selection}

Two sources were used to identify U.S.-based companies that had filed corporate sustainability reports that were also reasonable candidates to critique on the basis of the GRI reporting framework and the Greenhouse Gas Protocol. One source was CorporateRegister.com and the other, import data adapted from the Journal of Commerce (Rodrigue, et al., 2013).

Both sources support the selection of the consumer goods industry not only because they were the second largest group filing corporate sustainability reports in 2011 with Corporate Register, but also because they constitute the top U.S. importers.

The process of selecting the consumer goods industry began by first categorizing the companies that filed reports with Corporate Register in 2011 by SIC and NAICS codes. Beginning with the approximately 562 companies that filed reports with the Corporate Register, the list was reduced to include only companies with readily 
available NAICS and SIC codes, resulting in 491 organizations. These included government and educations as well as insurance companies and banks.

Table 1. Type of companies filing CSR reports with corporate register, 2011

\begin{tabular}{llll}
\hline Category & Number & Category & Number \\
\hline Aircraft Manufacturing & 6 & Industrial & 1 \\
Associations & 3 & Instrument & 5 \\
Automobile Manufacturing and Retail & 6 & Insurance & 19 \\
Banking & 28 & Medical & 16 \\
Beverage Production & 4 & Metal processing & 9 \\
Boat Manufacturing & 1 & Mining & 5 \\
Brewery & 3 & Miscellaneous & 1 \\
Chemical Processing & 14 & Motorcycle Production & 1 \\
Cigarette Production & 1 & Paper & 15 \\
Coffee and Tea & 2 & Pharmaceutical & 11 \\
Communication & 12 & Professional services & 26 \\
Computer Manufacturing and Retail & 22 & Property management & 8 \\
Construction & 11 & Publishing & 12 \\
Consumer goods & 44 & Rubber Manufacturing & 3 \\
Education & 9 & Sewage & 1 \\
Electronics Manufacturing and Retail & 11 & Transportation & 18 \\
Energy & 80 & Travel & 3 \\
Entertainment & 4 & TV/cable & 4 \\
Equipment/Machinery Production & 14 & Vending & 2 \\
Food Production and Retail & 33 & Water Treatment & 2 \\
Furniture Production & 8 & Water and Sewage & 1 \\
Glass Production & 1 & Winery & 1 \\
Government & 5 & Wood & 2 \\
Hazardous waste & 2 & & \\
\hline
\end{tabular}

As shown in Table 1, the organizations were categorized somewhat broader with the aid of SIC codes and categorization by the author, resulting in 33 categories.

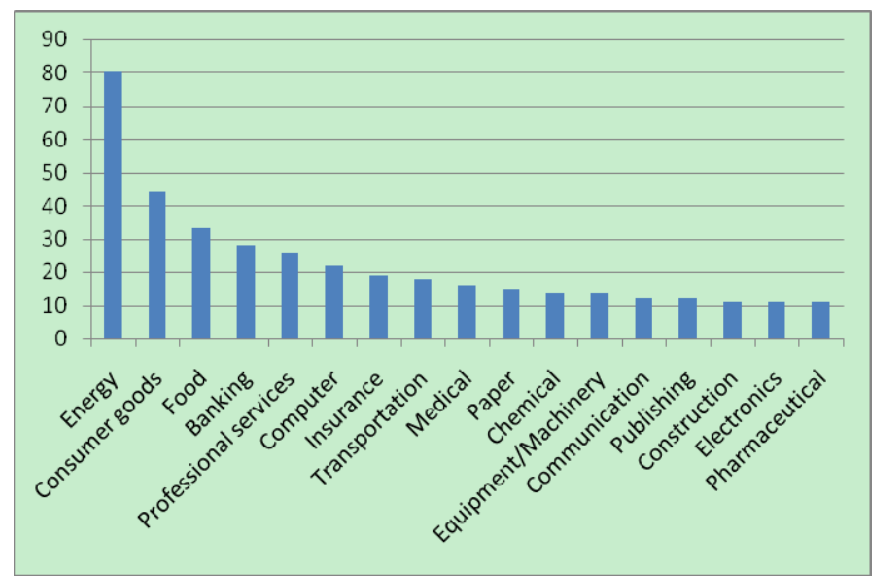

Figure 1. Reports filed by industry

Figure 1 shows the number of reports filed with Corporate Register.com by the top 17 industries listed in Table 1 .

After energy, the companies most frequently represented in the Corporate Register were consumer goods. In 2010, the top 5 largest importers into the U.S. in terms of truckload equivalent units (TEUs) as identified by Rodrigue (2013) were consumer goods retailers: 


\section{Target: 455,500 TEUs}

\section{Home Depot: 296,700 TEUs}

4. Lowe's: 221,600 TEUs

\section{Sears Holding: 212,800 TEUs}

Given the prevalence of the consumer goods industry, both in terms of number of reports filed with Corporate Register, and the volume of U.S. imports, this category was selected for review. It is also worth noting that of the 5 top importers into the U.S., Wal-Mart, Target and Lowe's filed sustainability reports with Corporate Register in 2011 .

Table 2. Consumer goods companies filing reports with the corporate register, August 2011

\begin{tabular}{|c|c|c|c|}
\hline Company Name & Supply Chain Role & NAICS code & SIC code \\
\hline Hanesbrands Inc & Manufacturing & 313312 & 2389 \\
\hline Mohawk Industries Inc & Manufacturing & 314110 & 2273 \\
\hline Phillips-Van Heusen Corporation & Manufacturing & 315223 & 2321 \\
\hline Nike Inc & Manufacturing & 316211 & 3021 \\
\hline Church \& Dwight Co Inc & Manufacturing & 325611 & 2841 \\
\hline Procter \& Gamble Inc & Manufacturing & 325611 & 2841 \\
\hline SC Johnson \& Son Inc & Manufacturing & 325611 & 2841 \\
\hline Diversey Inc & Manufacturing & 325612 & 2842 \\
\hline Ecolab Inc & Manufacturing & 325612 & 2842 \\
\hline The Clorox Company & Manufacturing & 325612 & 2842 \\
\hline Alberto-Culver Company & Manufacturing & 325620 & 2844 \\
\hline Aveda Corporation & Manufacturing & 325620 & 2844 \\
\hline The Estée Lauder Companies Inc & Manufacturing & 325620 & 2844 \\
\hline Armstrong World Industries Inc & Manufacturing & 326199 & 3089 \\
\hline Cascade Engineering & Manufacturing & 326199 & 3089 \\
\hline Tupperware Brands Corporation & Manufacturing & 326199 & 3089 \\
\hline Conwed Plastics LLC & Manufacturing & 326199 & 3089 \\
\hline Newell Rubbermaid Inc & Manufacturing & 326299 & 3089 \\
\hline Corning Inc & Manufacturing & 327213 & 3357 \\
\hline Whirlpool Corporation & Manufacturing & 335228 & 3639 \\
\hline Hasbro Inc & Manufacturing & 339932 & 3944 \\
\hline OfficeMax Incorporated & Wholesale & 424120 & 5112 \\
\hline Seventh Generation Inc & Wholesale & 424130 & 5113 \\
\hline Cardinal Health Inc & Wholesale & 424210 & 5122 \\
\hline Frontier Natural Products Co-op & Wholesale & 424210 & 5122 \\
\hline McKesson Corporation & Wholesale & 424210 & 5122 \\
\hline Anvil Knitwear Inc & Wholesale & 424330 & 5137 \\
\hline Best Buy Co Inc & Retail & 443112 & 5731 \\
\hline Lowe's Companies Inc & Retail & 444110 & 5211 \\
\hline CVS Caremark Corporation & Retail & 446110 & 5912 \\
\hline Chico's FAS Inc & Retail & 448120 & 5621 \\
\hline Nordstrom Inc & Retail & 448140 & 5651 \\
\hline Tiffany \& Co & Retail & 448310 & 5944 \\
\hline Recreational Equipment Inc & Retail & 451110 & 5941 \\
\hline JC Penney Company Inc & Retail & 452111 & 5311 \\
\hline Kohl's Corporation & Retail & 452111 & 5311 \\
\hline Macy's Inc & Retail & 452111 & 5311 \\
\hline Wal-Mart Stores Inc & Retail & 452111 & 5311 \\
\hline Target Corporation & Retail & 452990 & 5331 \\
\hline Staples Inc & Retail & 453210 & 5943 \\
\hline Bed Bath \& Beyond Inc & Retail & 453220 & 5947 \\
\hline Office Depot & Retail & 453998 & 5999 \\
\hline
\end{tabular}

The complete list of U.S.-based consumer goods companies that filed reports with Corporate Register are shown in Table 2. Table 2 also includes the role in the supply chain, designated as manufacturing, wholesale, or retail. 
Table 3. List of reports reviewed

\begin{tabular}{|c|c|c|c|}
\hline Company Name & Supply Chain Role & SIC code & Reason for inclusion \\
\hline Hanesbrands Inc & Manufacturing & 2389 & Sole SIC code \\
\hline Mohawk Industries Inc & Manufacturing & 2273 & Sole SIC code \\
\hline Phillips-Van Heusen & Manufacturing & 2321 & Sole SIC code \\
\hline Nike Inc & Manufacturing & 3021 & Sole SIC code \\
\hline Proctor \& Gamble Inc & Manufacturing & 2841 & SIC code "representative" and Wal-Mart supplier \\
\hline SC Johnson \& Son Inc & Manufacturing & 2841 & Wal-Mart supplier \& "model" for Scope 3 emissions \\
\hline The Clorox Company & Manufacturing & 2842 & SIC code "representative" and Wal-Mart supplier \\
\hline The Estée Lauder Company & Manufacturing & 2844 & SIC code "representative" \\
\hline Tupperware Corporation & Manufacturing & 3089 & SIC code "representative" \\
\hline Corning Inc & Manufacturing & 3357 & SIC code "representative" \\
\hline Whirlpool Corporation & Manufacturing & 3639 & SIC code "representative" \\
\hline Hasbro Inc & Manufacturing & 3944 & SIC code "representative" \\
\hline OfficeMax Incorporated & Wholesale & 5112 & SIC code "representative" \\
\hline Seventh Generation Inc & Wholesale & 5113 & SIC code "representative" \\
\hline McKesson Corporation & Wholesale & 5122 & SIC code "representative" \\
\hline Anvil Knitwear Inc & Wholesale & 5137 & SIC code "representative" \\
\hline Best Buy Co Inc & Retail & 5731 & SIC code "representative" \\
\hline Lowe's Companies Inc & Retail & 5211 & SIC code "representative" and top US importer \\
\hline CVS Caremark Corporation & Retail & 5912 & SIC code "representative" \\
\hline Nordstrom Inc & Retail & 5651 & SIC code "representative" \\
\hline Recreational Equipment Inc & Retail & 5941 & SIC code "representative" \\
\hline Wal-Mart Stores Inc & Retail & 5311 & SIC code "representative" and top US importer \\
\hline Target Corporation & Retail & 5331 & SIC code "representative" and top US importer \\
\hline Staples Inc & Retail & 5943 & SIC code "representative" \\
\hline Sears Holding & Retail & & Top US importer \\
\hline Home Depot & Retail & & Top US importer \\
\hline
\end{tabular}

Of the 42 companies listed in Table 3, several have identical SIC codes. Therefore, "representative" companies were selected for review. The last column of Table 3 indicates the rationale for selecting a particular company. For example, there is only 1 company, Hanesbrands, with the SIC code, 2839. Since there are no others with this particular code, this company is included. However, there are 3 companies with the SIC code 2842. Of the 3, Clorox was selected because of it size and the fact that it is a supplier to the largest importer of goods to the U.S., Wal-Mart. Similarly, there are 3 companies with the SIC code of 2841. Two of these-Proctor and Gamble and SC Johnson were both selected. Proctor and Gamble was selected because of their supplier relationship with Wal-Mart, and SC Johnson was selected because it is used as an example for the Scope 3 Reporting Standard (WRI \& WBCSD, 2011). Table 3 also includes Sears and Home Depot, two of the 5 largest importers of goods into the U.S.

In order to identify discrepancies in reporting, the criteria used to assess the reports are based on the reporting guidelines, discussed in the next section.

\subsection{Criterion Selection}

The criteria used to assess the company reports are based on the GRI guidelines, the GHG protocol, and company reporting practices. Broadly, these include carbon emissions and greenhouse gas emissions. Additionally, the reports are also reviewed for the inclusion of the environmental impacts of transportation and distribution of goods. The criteria for assessing the environmental impact of transportation include EN 29 from the GRI framework, and Scope 1 (direct) and Scope 3 (upstream/downstream transportation) emissions from the GHG Protocol.

The GRI environmental indicator EN29 states that companies should report on "significant environmental impacts of transporting products and other goods and materials used for the organization's operations, and transporting members of the workforce" (Global Reporting Initiative. Sustainability Reporting Guidelines, 2000-2011).

The Reporting Standard for the Greenhouse Gas Protocol specifies that transportation-related emissions be reported in the Scope 1 Direct emissions, which includes company vehicles; and the Scope 3 indirect emissions, which includes upstream and downstream activities associated with transportation and distribution. 
Other criteria are based on reporting practices by the companies themselves. For example, some companies reported total carbon emissions as total metric tons (tonnes) or total tons; emissions savings from previous year either in tons (or metric tons) of carbon, or miles eliminated and car-equivalent savings. Companies often combine different categories of emissions, reporting the contribution of carbon sources in percentages rather than absolute carbon output.

The next section provides an overview of reporting practices, identifying similarities and differences between the companies.

\section{Results}

Of the 26 reports reviewed, 12 adopted the GRI framework, 5 reported greenhouse gases in accordance with the GHG protocol, and 9 used another framework. Some used both.

All companies discussed initiatives associated with the reduction in carbon emissions and greenhouse gases. Some reported only carbon emissions, some only greenhouse gases, and some reported both. Many also reported savings from the previous year, or from a benchmark that may have been several years prior to the current report.

Table 4. Summary of reported carbon and greenhouse gas emissions

\begin{tabular}{|c|c|c|c|c|}
\hline \multirow[t]{2}{*}{ Company } & \multirow[t]{2}{*}{ Carbon emissions $\left(\mathrm{CO}_{2}\right)$} & \multicolumn{3}{|c|}{ Greenhouse Gas Emissions (reported as GHG unless otherwise noted) } \\
\hline & & $\begin{array}{l}\text { Direct } \\
\text { (Scope 1) }\end{array}$ & $\begin{array}{l}\text { Indirect } \\
\text { (Scope 2) }\end{array}$ & $\begin{array}{l}\text { Scope } 3 \text { (upstream/ downstream } \\
\text { transportation) }\end{array}$ \\
\hline Hanesbrands Inc & $\begin{array}{l}27,709 \text { tonnes from } \\
\text { distribution } \\
10,500 \text { tonnes from } \\
\text { transportation }\end{array}$ & 84,138 tonnes $\mathrm{CO}_{2}$ & 324,929 tonnes $\mathrm{CO}_{2}$ & 171,247 tonnes $\mathrm{CO}_{2}$ \\
\hline Mohawk Industries & 580,314 tonnes total & $1,130,000$ tonnes & 858,850 tonnes & \\
\hline Phillips-Van Heusen & 1820 tons (vehicle miles) & & & \\
\hline Nike Inc & \multicolumn{4}{|c|}{ Reported emissions savings } \\
\hline Proctor \& Gamble & & $2,800,00$ tonnes & $3,000,000$ tonnes & \\
\hline SC Johnson \& Son & & & & $\begin{array}{l}9 \% \text { of total for upstream } \\
\text { transport and } 9 \% \text { for } \\
\text { downstream transport }\end{array}$ \\
\hline The Clorox Company & $\begin{array}{l}505,000 \text { tonnes total } \\
150,000 \text { tonnes for } \\
\text { transportation }\end{array}$ & 75,000 tonnes & 283,000 tonnes & 148,000 tonnes for distribution \\
\hline Estée Lauder & & 32,742 tonnes & 63,768 tonnes & 44,866 tonnes \\
\hline Tupperware & & 15,000 tonnes & 17,000 tonnes & \\
\hline Corning Inc & \multicolumn{4}{|c|}{$1,475,000$ tonnes - direct and indirect } \\
\hline Whirlpool Corporation & & 218,729 tonnes & 541,314 tonnes & \\
\hline Hasbro Inc & & 19,684 tonnes & 7,656 tonnes & \\
\hline OfficeMax & \\
\hline Seventh Generation & \multicolumn{4}{|c|}{ Reported 10,885 tonnes GHG for product transport; 412 tonnes for employee/business travel. } \\
\hline McKesson Corp. & \multicolumn{4}{|c|}{ Reported carbon savings } \\
\hline Anvil Knitwear Inc & \multicolumn{4}{|c|}{42,319 tons for Scope 1 and 2} \\
\hline Best Buy Co Inc & \multicolumn{4}{|c|}{ Discussed initiatives and reported emissions savings } \\
\hline Lowe's & \multicolumn{4}{|c|}{ Discussed sustainability policy and energy savings in stores } \\
\hline CVS Caremark & $1,800,500$ tonnes & & & \\
\hline Nordstrom Inc & \multicolumn{4}{|c|}{ Discussed initiatives to reduce emissions } \\
\hline Recreational Equipment & \\
\hline Inc & \multicolumn{4}{|l|}{$\begin{array}{l}12,307 \text { product transport } \\
6,963 \text { direct fulfillment } \\
6,110 \text { corporate travel } \\
18,443 \text { employee } \\
\text { commuting }\end{array}$} \\
\hline Wal-Mart Stores Inc & \multirow{2}{*}{\multicolumn{4}{|c|}{ Discussed initiatives to improve transportation efficiency }} \\
\hline Target Corporation & & & & \\
\hline Staples Inc & \multicolumn{4}{|l|}{516,000 million tonnes } \\
\hline Sears Holding & & & $\begin{array}{l}4 \% \text { decrease from } \\
\text { previous year }\end{array}$ & \\
\hline Home Depot & & 281,083 tonnes & $2,738,927$ tonnes & \\
\hline
\end{tabular}

Table 4 summarizes the findings. The first 12 companies listed are manufacturers; the second 4, wholesalers; and the last 10 , retailers. The first column contains the carbon emissions reported and, where appropriate, the 
breakdown by category if this information was supplied by a reporting company. The last 3 columns contain reporting information for Greenhouse Gas Emissions for Scope 1, Scope 2, and Scope 3 emissions. Although some companies provided no emissions data their reports did contain discussions regarding goals and initiatives,

The summary presented in Table 4 illustrates the varying levels of reporting, which appears to be most thorough for manufacturers. Of the 12 manufacturers, nine reported emissions in at least two of the four categories. Nike's most recent report contained no emissions information, and Philips Van Heusen and SC Johnson reported in only one category. Of the four wholesalers, only one reported no emissions, and the others reported in at least 1 category. Most retailers reported in one category, with Home Depot reporting both Scope 1 and Scope 2 emissions, while Target, Nordstrom, Lowes, and Best Buy reported no emissions.

Table 5. Reporting summary

\begin{tabular}{llllll}
\hline $\begin{array}{l}\text { Supply Chain } \\
\text { Position }\end{array}$ & $\begin{array}{l}\text { Number of } \\
\text { companies }\end{array}$ & $\begin{array}{l}\text { Number reporting } \\
\text { total CO2 } \\
\text { emissions }\end{array}$ & $\begin{array}{l}\text { Number reporting } \\
\text { Scope 1 GHG } \\
\text { emissions }\end{array}$ & $\begin{array}{l}\text { Number reporting } \\
\text { Scope 2 GHG }\end{array}$ & $\begin{array}{l}\text { Number reporting } \\
\text { Scope 3 GHG }\end{array}$ \\
\hline Manufacturing & 12 & 2 & 9 & 9 & 3 \\
Wholesale & 4 & 1 & 2 & 2 & 0 \\
Retail & 10 & 4 & 1 & 1 & 0 \\
\hline
\end{tabular}

Table 5 summarizes these results. Although a small sample size, the upstream supply chain partners more frequently report greenhouse gases then the downstream echelons.

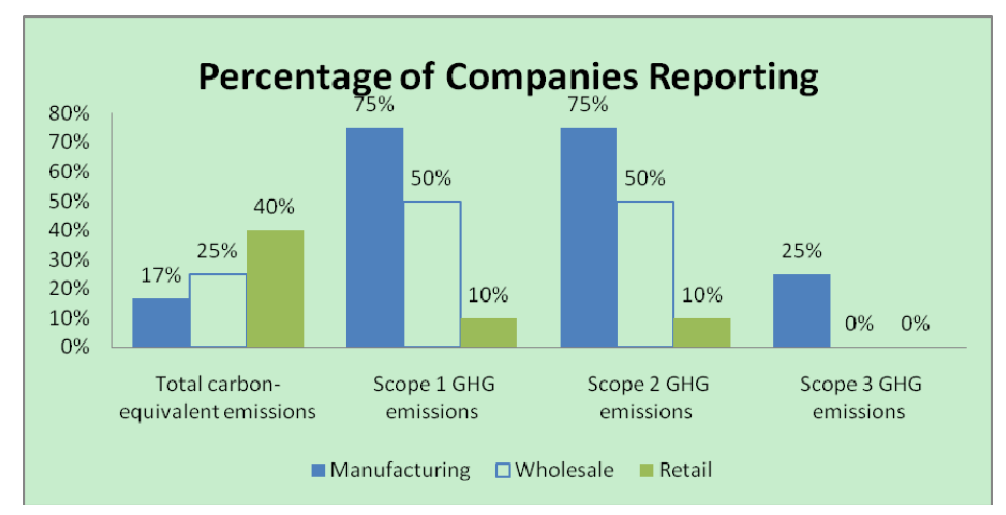

Figure 2. Emissions reporting by supply chain position

Figure 2 shows the percentages of companies reporting in each category. The summaries in Table 5 and Figure 2 show the inconsistent reporting practices of the selected companies. A closer look, however, also reveals some interesting results, reported in the next section.

\section{Discussion of Findings}

Not only do companies differ in terms of the type of emissions reported - total $\mathrm{CO}_{2}$, and Scope 1,2 or $3 \mathrm{GHG}$ emissions, but also in terms of the extent of the information reported. Some companies simply discussed their initiatives, whereas others provided detailed information about where the greatest emissions occurred. For example, Clorox reported emissions of 505,000 tonnes of $\mathrm{CO}_{2}$ equivalent in 2011, of which 150,000 tonnes were for transportation. Proctor and Gamble did not report total $\mathrm{CO}_{2}$ emissions. They did, however, report air emissions that included volatile organic compounds, carbon monoxide, nitrates and sulfates of 13,000 tonnes for 2012, not shown in Table 4 because Proctor and Gamble was the only company reporting on these specific types of emissions. As a result, it is not possible to compare Clorox and Proctor and Gamble's environmental performance. Proctor and Gamble reports emissions for air transportation whereas Clorox reports emissions for all operations.

Based on the summary presented in Table 4, it is readily apparent that the reporting of emissions between companies, even companies in the same supply chain role, cannot be compared due to the diverse methods used in measuring those emissions. It is worth noting that the intent of the reports, however, may not be to compare 
companies with each other. Nevertheless, if standards are applied consistently among all companies, it seems to be a reasonable expectation. Otherwise, can it really be a standard?

In terms of transportation reporting, only 4 companies-Hanesbrands, Clorox, REI, and Seventh Generation reported emissions resulting from product transportation and distribution even though six companies explicitly stated that they reported on Aspect EN 29 of the GRI framework. Philips Van Heusen also reported emissions due to vehicle miles, but it is not clear if this is from transportation of goods, business travel, or employee commuting.

Of the 5 largest importers, only Wal-Mart reported carbon equivalent emissions. These importers are all "Big Box" retailers whose goods are produced predominantly in China and transported to the U.S. through the West Coast ports, generating carbon emissions for transportation. According to Corbett (date not provided), transporting one TEU for one mile via water generates carbon emissions of 292.83 grams. Converting each of the imported TEUs into carbon equivalent results in the following emissions for these top 5 importers (Note 1):

Table 6. Carbon emissions for transporting goods across Pacific Ocean

\begin{tabular}{lll}
\hline Importer & $\begin{array}{l}\text { Carbon equivalent (metric tons) for } \\
\text { transportation from Shanghai to Port of Los } \\
\text { Angeles }\end{array}$ & Carbon equivalent emissions reported \\
\hline Wal-Mart & $1,324,763$ & $22,000,000$ \\
Target & 866,966 & Not reported \\
Home Depot & 564,737 & GHG reported for Scope 1 and 2 only \\
Lowe's & 421,792 & Not reported \\
Sears Holding & 405,042 & Not reported \\
\hline
\end{tabular}

Clearly, there are reporting gaps. Only Wal-Mart uses the GRI framework and indicates that they report on EN29, the environmental aspect of transportation. Target and Home Depot report following the GHG Protocol and Lowe's and Sears do not indicate using any framework. Clearly, transportation impacts of 4 of the 5 top importers are excluded from their sustainability reports.

Not only do inconsistencies exist between different companies, but also between subsequent reports for a given company. For example, SC Johnson will be "shifting our measurement reductions on an absolute basis to reductions indexed to production" (SC Johnson, 2012). Doing so provides higher percentages of savings. On an absolute basis, SC Johnson cut emissions from global factories by $26 \%$ since 2000 , equivalent to $42 \%$ when indexed to production (ibid.). Similarly, Nike also modified their reporting between FY 07-09 and FY 2011. For example, in their earlier Corporate Responsibility Report, Nike reported total freight transportation emissions of 355,800 $\mathrm{CO}_{2}$ emissions (Nike, 2011). In FY 2011, however, Nike states that, "While we have worked with our shipping partners to optimize transportation choices, this effort has not resulted in an absolute reduction in emissions" (Nike, 2012). Further, they report emission reductions on a per-unit basis and indicate that their emissions were far above their targets in FY 11 due to capacity constraints in their factories which required additional air freight.

These two examples help to illustrate the challenges companies face when growth and revenues result in emissions increases. As the "low-hanging" fruit for energy and emission savings is depleted, it becomes increasing challenging for companies to further reduce their carbon footprints and GHG emissions. Rather than report on the absolute changes in these emissions, companies face more favorable public perceptions by changing the reporting metrics and discussing initiatives. Favorable public perception may also be improved when companies discuss their carbon savings.

Companies that report carbon savings often do so in the context of how many cars are removed from the highways. The most common conversion factor appears to be about 5.2 cars per tonne of carbon. The reported savings, however, may span 1 or more years. Therefore, comparison between companies is not possible. Nevertheless, reporting savings in terms of cars removed from the highways is helpful to the consumer in assessing the reduction, as reporting absolute changes in terms of tonnes of carbon is difficult to visualize. Of the companies reporting savings, Wal-Mart reported the largest, at an equivalent of 7900 cars over a 1-year time period. To put this into perspective, consider that the number of registered cars in California in 2007, the most recent year available, was about 22 million (California Department of Finance, 2009). Using this conservative estimate, the reduction of 7900 cars is equivalent to a reduction of $.036 \%$ in the number of cars in California, a relatively small amount. 
Finally, some company reports appear erroneous. For example, Staples reported total emissions of 516,000 million metric tons compared to Wal-Mart's reported 22 million metric tons. By comparison, Staples' emissions seem extremely high —or other companies are vastly underreporting their emissions.

Given the myriad of reporting gaps, omissions and practice, a reasonable question is, "What constitutes a good report?" It seems reasonable to expect that companies receiving awards for their reports would be the most thorough, at least in terms of adherence to reporting standards. In 2012, Coca Cola received the Best Report Award from the Corporate Register for their European operations. (Corporate Register, 2012) Users of Corporate Register vote on the best reports using the criteria of content, communication, credibility, commitment, and comparability. There were a total of 45 submissions and over 6000 votes were cast. Coca Cola's winning report contained the following elements:

- Carbon savings (absolute) from previous year

- Carbon footprint by country in 2010: Great Britain, France, Luxembourg, Netherlands

- Carbon footprint from 2007 to 2010 by categories, which included manufacturing and third-party distribution

- 2010 emissions by scope $(1,2$, or 3 ) and source (type of greenhouse gas)

- Carbon emissions for the value chain: ingredients, packaging, manufacturing, distribution, selling-cooling and vending.

- Initiatives to reduce transportation emissions, including reported savings over a 1-year period.

Compared to the top 5 importers of U.S. goods, the report by Coca Cola is far more thorough, although it does not address their global operations. They reported specifically on transportation, provided a breakdown of their carbon footprint both geographically and operationally, thoroughly reported on their greenhouse gases, identified carbon savings in absolute terms, and discussed their longer term plans.

Studies have shown that a firm's engagement in CSR and financial performance are positively linked. Jo and Harjoto (2011) show that not only do CSR activities increase a firm's value, but also that if those activities are linked to internal social objectives, the value of the firm is enhanced more than for corporate performance resulting from environmental improvements or community engagement. Scholtens (2008) also showed a link between a firm's value and its demonstrated commitment to social performance, suggesting that financial performance was a precursor to social performance. Although this study addressed environmental reporting, an interesting contrast could emerge if these reports were analyzed for the depth and breadth of their social performance reporting.

Given the voluntary nature of environmental reporting, incentives to disclose information, especially information that demonstrates a lack of progress in reducing carbon and greenhouse gas emissions, appear to be based primarily on public perception. Perhaps it would behoove companies to make separate reports - one for internal use to track true progress, and another to disseminate to stakeholders. However, without incentives to track environmental performance, one wonders why a company would invest in collecting data that may or may not be readily available or easily obtained. For a smaller company, collecting such data may be economically prohibitive. Additionally, if environmental performance is deemed to be lower than what is expected by stakeholders, especially by the critical public eye, then flexible reporting frameworks and measures will better protect the company from publicizing environmental mishaps and blunders.

The quality of a corporate environmental report (CER) may be influenced by several forces, worthy of further investigation. 


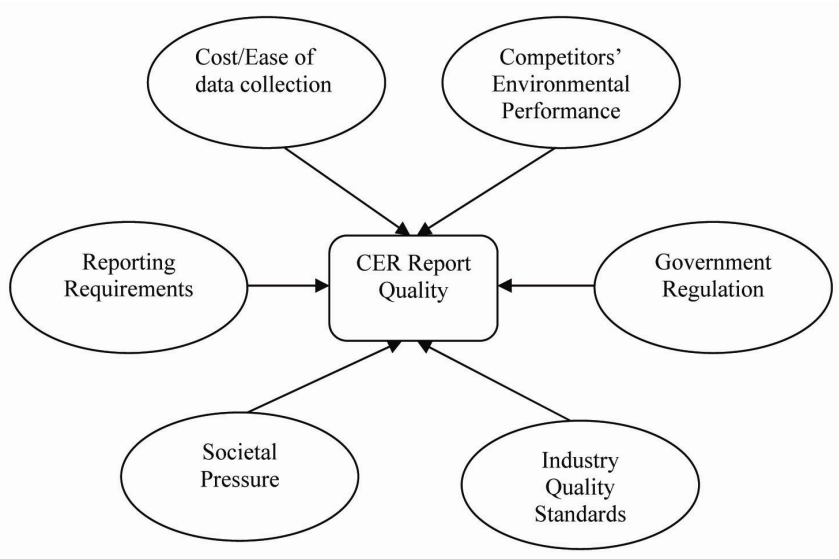

Figure 3. Factors affecting quality of environmental reports

Figure 3 presents these ideas in a conceptual framework. For one, the reporting requirements will affect the quality of the environmental report itself. Companies may choose between existing frameworks or modify a framework to suit their needs. As reported earlier, those countries that lead the world in reporting are also the least likely to use the reporting framework provided by GRI (CR Reporting Awards, 2012). Another factor, societal pressure, may also be expressed through the activities of non-governmental organizations, government regulations and industry quality standards. These regulations and standards depend on the power wielded by society, which can be markedly different between industrialized and developing countries. For example, in the U.S., citizens may be more concerned with a company's environmental performance than social performance due to regulatory oversight that affords workers reasonable protection in the U.S. The emphasis may be very different in developing countries, where workers may be exploited and living and/or working in poor and unsafe conditions. Therefore, for multinational companies that are headquartered in industrialized nations, the emphasis on social performance over environmental performance may reflect societal preferences.

Industry quality standards such as ISO 14000 can also affect environmental reporting because compliance requires that processes be documented and measured, contributing to the data-gathering necessary for environmental reporting. The same is also true of government regulatory agencies such as the U.S. Environmental Protection Agency and the California Air Resources Board. The quality of competitors' environmental reports may also impact the overall quality within a particular industrial sector. For example, in spite of technological advances in alternative fuels and cleaner-burning engines, companies have been slow to report on the contribution of these advancements toward reducing environmental impacts, particularly in absolute terms. Almost all reports contain some reference to reduction in energy use through building design, reduced emissions through cleaner fuels and combustion technology, and improved environmental performance as a result of adopting new manufacturing technologies. Finally, the ease and cost of collecting data is also an important consideration. If data is not gathered in order to meet regulatory or industry standards, then the only incentive to collect it would be for internal information or for environmental reporting.

The problem, of course, lies partly within the global nature of environmental reporting. What may work for a company based in the U.S. may not be appropriate for a small company operating in Africa. The same could also be said of companies at different stages of maturity and companies that make different products. Some products could be considered environmentally burdensome - such as resource-based industries, energy and chemical companies - requiring greater oversight and reporting compared to products that may be deemed "sustainable".

Given all of the factors that affect environmental reporting, one possibility is to rely not on companies to report all of their environmental impacts, but existing government agencies. For example, the U.S. can use trade information to determine the impact of transporting imports and exports through land, sea, and inland ports. Similarly, transportation agencies can report movement of goods by various modes, relieving companies from the burdensome task of identifying all goods movement and environmental impacts. This would address both the problem of omission and double counting. Implementation challenges notwithstanding, this approach may be useful to address the impact of transporting and distributing goods to, from, and within the U.S., an approach that may not be feasible for all countries. 


\section{Conclusion}

In spite of the creation of reporting guidelines for environmental impacts of production activities, there remain inconsistent reporting practices, both between different companies and between annual reports for specific companies. In summary, the following problems seem to be prevalent:

- Incomplete reporting of carbon emissions and greenhouse gases, often omitting emissions resulting from transportation and distribution

- Inconsistent performance metrics - emissions reported as metric tons, tons, emissions per dollars revenue; emissions reported as percent of total with no total reported

- Inconsistent time frames for reported savings, varying from annual savings to savings reported from a base year that extends more than 5 years from the present

- Inconsistent reporting practices between a particular company's annual reports, resulting in ineffective comparisons from year to year

- Inconsistent reporting practices between companies in the same industry, resulting in ineffective comparisons between companies

In spite of these problems, several companies appeared to thoroughly report on their environmental impacts of their operations, including transportation. These included REI, Clorox and Hanesbrands. In general, reporting the impacts of transportation and distribution activities was very marginal.

Sustainability reporting may increase accountability and transparency; however by the same token, the reporting mechanisms can be used to obfuscate declining performance by changing metrics, omitting information, or simply focusing on other aspects of Corporate Social Responsibility. For example, Tupperware's report focused on their global workforce and empowering women, an emphasis that supports their business model of a sales force of primarily women numbering over 2.7 million (Tupperware, 2012). Similarly Nike's report emphasizes sustainable materials, sourcing and manufacturing practices, educating consumers and other stakeholders regarding sustainable consumption, and finally, assisting athletes (Nike, 2012). Nike's report focuses on upstream supply chain activities compared to Tupperware, which focuses on downstream supply chain activities.

Corporate Sustainability Reports do little to help society or stakeholders determine the overall environmental impact of production and consumption activities of a company. Reports are voluntary, the standards unevenly applied, and some poorly understood. For example, one of the problems with transportation reporting is the possibility of "double-counting". This could occur if a manufacturer reports their downstream transportation impacts and their distributor also reports their upstream transportation impacts. The standards- both GRI and the GHG Protocol — do not adequately address this potential problem. It is the opinion of this author, however, that the prevalence of double counting is far less problematic than the prevalence of no reporting at all.

This analysis clearly points toward the limitations of Corporate Social Responsibility Reports in terms of environmental reporting. Perhaps these reports are more akin to "feel-good" public relations releases, linking production activities to environmental performance, measured by indicators that are flexibly applied. Nevertheless, environmental reporting has lead to the perception that companies are being more vigilant in terms of their environmental impacts, particularly in terms of product design, material selection, manufacturing practices, and facility operations. To what extent can the public expect corporations to take responsibility for their environmental impacts and to provide thorough complete reports? According to Milton Friedman, the function of business is to increase profits, not to engage in socially responsible activities (Friedman, 1970). Are we, as citizens, giving up our responsibility to be good stewards of the environment by abdicating our responsibility to provide reasonable oversight? Have we, as Robert Reich (2007) suggests, entered into a Faustian bargain? We may blame the corporations for environmental degradation, but we still purchase the goods that they produce. Are Corporate Sustainability Reports simply a mechanism to help us feel better by giving us the illusion that all is well?

If we are indeed to rely on corporate reports to address environmental problems, then we have a long way to go and perhaps the current path-CSR - is unsustainable. The reports are too piecemeal, the participants too few, and the coverage too thin, to provide meaningful insights into the environmental performance of global production and consumption activities. CSR has a role, but in this author's opinion, it is a role that is useful for creating a positive public image, not necessarily a role that demonstrates environmental stewardship.

Is it reasonable to go so far as to suggest that CSR is simply greenwashing? For some companies, absolutely. For others, maybe not. Public pressure requires that companies, especially well-known companies, provide public 
reports about their commitment to social and environmental issues. For some, this may simply be a collection of "feel-good" initiatives, a few statistics, and highlights of accomplishments in product and process design, energy saving programs, employee satisfaction, and consumer protection. For others, it may be a true attempt to capture, track, and improve environmental performance. For many, annual reports seem to be loosely linked to previous reports, so long term performance cannot often be evaluated.

CSR Reporting will continue to grow, and the quality of reports will likely be as variable as companys' financial performance. A voluntary effort, CSR reporting is good business for many, greenwashing for a few, and perhaps a distraction for citizens who really do care about environmental impacts of global production and consumption activities.

\section{References}

California Department of Finance. Calfornia Statistical Abstract. (2009). Table J-4. Retrieved from $\mathrm{http}: / /$ www.dof.ca.gov/html/fs_data/STAT-ABS/Toc_xls.htm

Corbett, J., Winebrake, J., Hatcher J., Farrell, A. (n. d.). Emissions Analysis of Freight Transport Comparing Land-Side and Water-Side Short-Sea Routes: Development and Demonstration of a Freight Routing and Emissions Analysis Tool (FREAT). Prepared for the United States Department of Transportation, Research and Special Programs Administration (Under DTRS56-05-BAA-0001 Full Proposal).

Corporate Register. (2012). CR Reporting Awards-Global Winners \& Reporting Trends. Retrieved from http://www.corporateregister.com/a10723/45590-12th-11762220C1759774000T-Gl.pdf

Friedman, M. (1970). The Social Responsibility of Business is to Increase its Profits. New York Times Magazine, September 13, 1970.

Global Reporting Initiative. (2000-2011) Sustainability Reporting Guidelines, 2000-2011. Retrieved from https://www.globalreporting.org/reporting/latest-guidelines/g3-1-guidelines/Pages/default.aspx

Golicic, S., Boerstler, C., \& Ellram, L. (2010). Greening' Transportation in the Supply Chain. MIT Sloan Management Review, 51(2), 47-55.

Jo, H., \& Harjoto, M. (2011). Corporate Governance and Firm Value: The Impact of Corporate Social Responsibility. Journal of Business Ethics, 103, 351-383. http://dx.doi.org/10.1007/s10551-011-0869-y

Nike, Inc. (2010). Corporate Responsibility Report FY 07-09. Retrieved from http://nikeinc.com/news/nike-outlines-global-strategy-for-creating-a-more-sustainable-business

NIKE, Inc. (2012). FY10/11 Sustainable Business Performance Summary. Retrieved from http://www.nikeresponsibility.com/report/files/report/NIKE_SUSTAINABLE_BUSINESS_REPORT_FY 10-11_FINAL.pdf

Reich, R. B. (2008). Supercapitalism. New York, NY: Vintage Books.

Rodrigue, J., Claude C., \& Slack, B. (2013). The Geography of Transport Systems. Retrieved from http://people.hofstra.edu/geotrans/eng/ch5en/conc5en/americancontainerizedimports.html

Sanchez-Rodriugues, V., Potter, A., \& Naim, M. (2010). The impact of logistics uncertainty on sustainable transport operations. International Journal of Physical Distribution \& Logistics Management, 40(1/2), 61-83. http://dx.doi.org/10.1108/09600031011018046

SC Johnson. (2012). Green Choices. SC Johnson 2012 Sustainability Report. Retrieved from http://www.scjohnson.com/en/commitment/report.aspx

Scholtens, B. (2008). A note on the interaction between corporate social responsibility and financial performance. Ecological Economics, 68, 46-55. http://dx.doi.org/10.1016/j.ecolecon.2008.01.024

Tupperware, Tupperware Brands Sustainability Report. (2012). Retrieved from http://tupperwarebrands.com/sustainability/pdf/Sustainability_2012_Tupperware_Brands.pdf

World Resources Institute and World Business Council on Sustainable Development. (2011). Greenhouse Gas Protocol. Corporate Value Chain (Scope 3) Accounting and Reporting Standard. Retrieved from http://www.ghgprotocol.org/standards/scope-3-standard 


\section{Note}

Note 1. For Wal-Mart the carbon equivalent is computed as follows:

6500miles $* 696,000 T E U s * \frac{292.83 \text { grams }}{\text { TEU }- \text { mile }} * \frac{1 \text { tonne }}{1,000,000 \text { grams }}=1,324,763$ tonnes

\section{Copyrights}

Copyright for this article is retained by the author(s), with first publication rights granted to the journal.

This is an open-access article distributed under the terms and conditions of the Creative Commons Attribution license (http://creativecommons.org/licenses/by/3.0/). 